\title{
A ATUAÇÃO DOS CONSELHEIROS DE EDUCAÇÃO PARA O FORTALECIMENTO DA GESTÃO DEMOCRÁTICA
}

\author{
Elioenai Santos de Santana Farias ${ }^{1}$ \\ Emilia Peixoto Vieira ${ }^{2}$
}

\section{RESUMO}

O presente artigo tem como objetivo analisar a função e a atuação dos conselheiros de educação, visando o fortalecimento da gestão democrática da educação de um Sistema Municipal de Ensino (SME). Apresenta desde a institucionalização dos conselhos à atuação dos conselheiros, evidenciando os desafios para o acompanhamento da política educacional em um município na região sul da Bahia. A pesquisa foi desenvolvida numa perspectiva histórica e dialética, considerando a compreensão do universal e do particular, em uma relação do todo com as partes. No percurso metodológico utilizou-se da PesquisaAção defendida por Thiollent (2011). Os resultados da pesquisa assinalam que há desafios aos conselheiros de educação na condução de sua função no órgão, como a necessidade de conhecimento da lei e, portanto, de estudo da legislação educacional nacional e local. Ações conjuntas entre os conselhos de educação podem auxiliar a formação de conselheiros e a publicização das funções dos conselhos municipais de educação.

Palavras-chave: Conselhos de educação. Participação. Gestão democrática.

\section{THE ACTIONS OF EDUCATION COUNCIL MEMBERS FOR THE STRENGTHENING OF A DEMOCRATIC MANAGEMENT}

\section{ABSTRACT}

This article analyzes the role and performance of education council members as a way of strengthening the democratic management in a Municipal Education System (SME, in Portuguese acronym). This research presents both the institutionalization of councils and the performance of council members, highlighting the challenges in monitoring educational policies in a city in the southern region of Bahia. This work has a historical and dialectical perspective, considering the understanding of the universal and the particular, in a relationship of the whole with its parts. "Action Research", advocated by Thiollent (2011), was the chosen methodology. Results indicate that education council members face challenges when carrying out their

\footnotetext{
1 Mestre em Educação pela Universidade Estadual de Santa Cruz - UESC, Ilhéus, Bahia, Brasil. Orcid iD: https://orcid.org/0000-0003-3983-7660. E-mail: elioenaifarias@hotmail.com

2 Doutora em Educação pela Universidade Estadual de Campinas. Coordenadora do Programa de Pós-Graduação Mestrado Profissional em Educação/PPGE - Universidade Estadual de Santa Cruz - UESC, Ilhéus, Bahia, Brasil. Orcid iD: https://orcid.org/0000-0001-9718742X. E-mail: emilcarl28@hotmail.com
} 
functions, such as the need to know the laws and, therefore, to study national and local educational legislation. Joint actions between education councils can assist in the training of council members and in the disclosure of municipal education councils' functions.

Keywords: Education councils. Participation. Democratic management.

\section{LA ACCIÓN DE LOS ASESORES EN EDUCACIÓN PARA FORTALECER LA GESTIÓN DEMOCRÁTICA}

\section{RESUMEN}

Este artículo tiene como objetivo analizar el rol y desempeño de las orientadoras educativas, con el objetivo de fortalecer la gestión democrática de la educación en un Sistema Municipal de Enseñanza (PYME). Presenta desde la institucionalización de los concejos hasta la actuación de los concejales, destacando los desafíos para el seguimiento de la política educativa en un municipio de la región sur de Bahía. La investigación se desarrolló con base en una perspectiva histórica y dialéctica, considerando la comprensión de lo universal y lo particular. En la vía metodológica se utilizó la Investigación Acción propugnada por Thiollent (2011). Los resultados del trabajo indican que existen desafíos para los consejeros educativos en el desempeño de su función en la agencia como la necesidad de conocer la ley y, por ende, de estudiar la legislación educativa nacional y local. Las acciones conjuntas entre los consejos de educación pueden ayudar a capacitar a los consejeros y dar a conocer las funciones de los consejos de educación municipales de una forma más eficiente y que fortalezcan la gestión democrática.

Palabras clave: Consejos de educación. Participación. Gestión democrática.

\section{INTRODUÇÃO}

O presente artigo objetiva analisar a função e a atuação dos conselheiros de educação, visando o fortalecimento da gestão democrática da educação de um Sistema Municipal de Ensino (SME). O Conselho Municipal de Educação (CME), o Conselho de Alimentação Escolar (CAE) e o Conselho de Acompanhamento e Controle Social do Fundo de Manutenção e Desenvolvimento da Educação Básica e de Valorização dos Profissionais de Educação (FUNDEB) fazem parte de Conselhos Municipais ligados à Educação, e portanto, os integrantes desses conselhos precisam atuar de forma a garantir a execução de políticas educacionais no âmbito municipal. Com esse entendimento, analisamos a atuação dos Conselheiros de Educação, em uma pesquisa realizada no 
decorrer do segundo semestre de 2018 e primeiro semestre de 2019, com 12 conselheiros municipais, eleitos e/ou indicados para as representações do governo e da sociedade civil em um município no sul da Bahia. A pesquisa iniciou com o estudo da estrutura dos conselhos de educação para responder a seguinte questão: que interação existe entre os conselhos de educação para o fortalecimento da gestão democrática no Sistema Municipal de Ensino (SME)? Com o objetivo geral de analisar a função e a atuação dos conselheiros de educação, visando o fortalecimento da gestão democrática da educação no Sistema Municipal de Ensino (SME).

A pesquisa foi desenvolvida numa perspectiva histórica e dialética, considerando a compreensão do universal e do particular, em uma relação do todo com as partes. O percurso metodológico adotado foi inspirado na Pesquisa-Ação defendida por Thiollent (2011), em que consiste resolver ou pelo menos esclarecer os problemas da situação observada, já que pressupõe a articulação entre o conhecer e o agir. Também se utilizou da análise de documentos legais e normativos e da revisão bibliográfica.

Estudos envolvendo Conselhos Municipais vêm procurando evidenciar a importância da temática, delineando cada vez mais as experiências dos conselhos de educação nos vários municípios do Brasil, o que requer a necessidade de melhor compreender a natureza e o funcionamento desses conselhos. Conforme afirma Santos (2014, p. 89), "uma vez inserido na estrutura do Estado, o conselho passa a ser entendido como órgão de Estado de articulação política entre representantes da sociedade civil organizada e sociedade política".

Com a finalidade de analisar o tratamento dado ao assunto no campo da produção acadêmica, e para atender ao foco do trabalho, analisar o papel e a atuação dos Conselheiros de Educação no âmbito da gestão democrática no sistema de ensino, realizamos uma revisão de literatura ${ }^{3}$, por meio de pesquisa no Banco de Teses e Dissertações da

${ }_{3}^{3}$ Mais detalhes das análises da revisão de literatura ver: FARIAS, Elioenai Santos de Santana. A Gestão Democrática e a Participação dos Conselheiros de Educação em Itabuna - Bahia. 
Coordenação de Aperfeiçoamento de Pessoal de Nível Superior (CAPES), nas produções realizadas entre 2010 a 2017, a respeito do papel e a atuação dos Conselhos Municipais de educação, utilizando os descritores: "gestão democrática" e "Conselhos Municipais".

Os estudos evidenciaram que ainda se faz urgente a necessidade de se melhor compreender a natureza e o funcionamento dos Conselhos de Educação, e a preocupação sobre a problemática da participação da sociedade local nos conselhos, visando, sobretudo, à intervenção social. Constatamos com o presente trabalho, que as pesquisas avançaram tanto em relação ao descritor "gestão democrática" quanto ao descritor "conselhos de educação", mas considerando a análise da participação dos três conselhos de educação (CME, CAE e FUNDEB) no sistema municipal, nenhum trabalho foi encontrado. Apenas por esse motivo, já visualizamos a necessidade de mais pesquisas abordando a possibilidade de interação entre os órgãos nos sistemas municipais de ensino e, principalmente, para o cumprimento da gestão-democrática.

Para que a gestão democrática se efetive, a participação precisa ser de fato uma realidade, desse modo, faz-se necessário meios, ações e condições que favoreçam a descentralização do poder e se instaure uma gestão construída coletiva e diariamente. Nessa direção, Dourado (2006) ressalta como fundamental que a participação não seja decretada, nem imposta e, portanto, que não seja entendida apenas como mecanismo formal, ritual e legal. A participação é compreendida como a organização e gestão cujo objetivo é criar as condições e mecanismos para que os diferentes sujeitos sociais possam atuar e interferir nos diferentes espaços de decisão das políticas educacionais.

A crescente participação da sociedade brasileira na gestão de políticas públicas ocorreu quase no final da década de 1980, com o fim da ditadura civil-militar, com um novo desenho nas formas de participação pela sociedade civil, viabilizando intervenção nos processos de tomada de em Educação, Universidade Estadual de Santa Cruz, llhéus, 2019. 
decisão sobre os assuntos educacionais, por meio de leis, resoluções, planos, metas, financiamento, alimentação, transporte, etc., por meio dos canais de participação institucionalizados como os comitês, as comissões e os conselhos organizados, a partir das políticas públicas instituídas.

Todavia, em consonância com os estudos de Cury (2006), entendemos que um conselheiro municipal de educação precisa ter postura de defensor da cidadania, logo seus estudos e investigações devem the conduzir a conhecimentos específicos e acumulativos para qualificar o exercício das atividades inerentes a sua função. O autor afirma que [...] "a autoridade derivada que the é imanente pela função não pode ignorar o que $\circ$ ordenamento jurídico dispõe e nem se contentar com um amadorismo ou certo diletantismo" (CURY, 2006, p. 42).

Diante desse contexto, o presente artigo está organizado em duas partes, além da presente introdução. Na primeira, apresentamos a caraterização do campo e os sujeitos da pesquisa, o que nos permitiu elencar as características que apontam o perfil dos conselheiros municipais de educação. Na segunda parte, trazemos o percurso metodológico que nos conduziu aos resultados da pesquisa e os desafios e perspectivas vivenciados no exercício da função de conselheiro da educação. Ao final são apresentadas as considerações finais.

\section{A CARACTERIZAÇÃO DO CAMPO E SUJEITOS DA PESQUISA}

O município integra o Território ${ }^{4}$ de Identidade Litoral Sul (TLS), e está localizado na região Sul da Bahia e a 431 quilômetros da capital. O TLS da Bahia é um território extenso, possui $14.664,70 \mathrm{~km}^{2}$, distribuídos em 26

\footnotetext{
4 A Regionalização de Territórios de Identidade foi adotada pela Secretaria de Planejamento do Estado da Bahia (SEPLAN) através da Lei $n^{\circ} 10.705$, de 14 de novembro de 2007, constituídos a partir da especificidade de cada região. Foi reconhecida pelo governo da Bahia, com o objetivo de identificar prioridades temáticas definidas a partir da realidade local, possibilitando o desenvolvimento equilibrado e sustentável entre as regiões (SEI Superintendência de Estudos Econômicos e Sociais da Bahia, 2018). É conceituado como um espaço físico, geograficamente definido, geralmente contínuo, caracterizado por critérios multidimensionais, tais como o ambiente, a economia, a sociedade, a cultura, a política e as instituições, e uma população com grupos sociais relativamente distintos, que se relacionam interna e externamente por meio de processos específicos, onde se pode distinguir um ou mais elementos que indicam identidade, coesão social, cultural e territorial.
} 
municípios: Almadina, Arataca, Aurelino Leal, Barro Preto, Buerarema, Camacan, Canavieiras, Coaraci, Floresta Azul, Ibicaraí, Ilhéus, Itabuna, Itacaré, Itajú do Colônia, Itajuípe, Itapé, Itapitanga, Jussari, Maraú, Mascote, Pau Brasil, Santa Luzia, São José da Vitória, Ubaitaba, Una, Uruçuca (BAHIA, 2018).

Teve o Sistema Municipal de Ensino criado pela Lei $n^{\circ} 1.968$, de 06 de outubro de 2005, nos termos que dispõe o Art. 211, da Constituição Federal/1988; Art. 8 , 1 1, 14, 15 e 18, da Lei de Diretrizes e Bases da Educação Nacional (LDB), Lei n 9.394/96, e Art. 26, das Disposições Transitórias, da Lei Orgânica do Município. Conforme a Lei n 1.968/2005, o Sistema Municipal de Ensino fica constituído pelo Órgão da Secretaria Municipal de Educação; Conselho Municipal de Educação; Instituições de Educação Infantil, Ensino Fundamental e Ensino Médio mantidas pelo Poder Público Municipal; e pelas Instituições de Educação Infantil, criadas e mantidas pela iniciativa privada.

Após análise documental, verificou-se a existência de 28 (vinte e oito) conselhos no município, dos quais a pesquisa focou em apenas três, por considerá-los com aproximação direta com a escola ou o sistema de ensino, ressaltando o propósito de conhecer as ações desses conselhos de educação. Nessa direção, apresenta-se um pouco de cada conselho e sua área de atuação no âmbito do sistema municipal de ensino.

O Conselho Municipal de Educação (CME) foi estruturado pela Lei $n^{\circ}$ 1.657/1994, com as devidas alterações, acréscimos e supressões através da Lei $n^{\circ}$ 2.372/2016. Composto em 2019 por 16 (dezesseis) representações que integram os diversos segmentos representantes do Poder Público Municipal e Sociedade Civil legalmente constituída, com a finalidade de formular as diretrizes e prioridades da política de Educação do Sistema Municipal de Ensino, exercendo funções normativas, consultivas, deliberativas, fiscalizadoras, mobilizadoras e de acompanhamento e controle social.

O Conselho Municipal de Alimentação Escolar (CAE) foi regulamentado pela Lei Municipal n 1.748/1997, composto em 2019 por 07 (sete) representações do Poder Público e da Sociedade Civil organizada. Instituído como órgão colegiado de caráter fiscalizador, permanente, 
deliberativo e de assessoramento, responsável pelo acompanhamento da utilização dos recursos repassados pelo Programa Nacional de Alimentação Escolar (PNAE), zelando pela qualidade da alimentação escolar.

O Conselho de Acompanhamento e Controle Social do Fundo de Manutenção e Desenvolvimento da Educação Básica e de Valorização dos Profissionais da Educação (FUNDEB) foi regulamentado pela Lei Municipal $n^{\circ}$ 2.319/2015, composto por 10 (dez) representações conforme especifica a Lei Federal $n^{\circ} 11.494$ de 20 de junho de 2007, em seu Capítulo VI, Art. 24, Parágrafo $1^{\circ}$, Inciso IV e Parágrafo $2^{\circ}$. Foi instituído como órgão colegiado que tem como finalidade acompanhar a repartição, transferência e aplicação dos recursos financeiros do FUNDEB no Município.

Quanto aos conselheiros e participação na pesquisa, todos os 66 membros dos três conselhos municipais foram convidados a participar da pesquisa, tanto os conselheiros titulares como os suplentes, que após conhecerem a finalidade da pesquisa, constituíram o grupo de conselheiros de educação que passaram a analisar a atuação dos conselhos no município e o princípio da gestão democrática na educação.Vale ressaltar, que mesmo não sendo propósito da pesquisa, na coleta de informações, constatamos vacância em algumas representações, representações com mandatos vencidos, entidades pendentes com 0 envio de suas representações e ainda, o absenteísmo de alguns conselheiros.

Para a coleta de informações sobre os referidos conselheiros de educação, foi elaborado um questionário, compreendendo quatro blocos de questões, que serviram de base para o diagnóstico. No primeiro bloco, denominado perfil dos sujeitos da pesquisa, considerou especificamente 0 conselho, segmento representado, duração do mandato, tempo de atuação, processo de eleição ou indicação, critérios que foram considerados para eleição ou indicação, motivação para aceitar a eleição ou indicação, relação estabelecida entre o tempo de atuação no conselho e à participação nas reuniões, e sobre a atuação em outros conselhos. O segundo bloco tratou da escolarização e da atividade profissional desenvolvida pelos conselheiros. O terceiro bloco, composto de apenas uma 
questão, abordou sobre a legislação educacional pertinente aos três conselhos e também, a uma legislação específica, oportunizando a descrição da finalidade de utilização dessa legislação no campo de atuação dos conselheiros. O quarto e último bloco, abordou sobre o processo de formação para conselheiro, e os desafios e perspectivas vivenciados no exercício da função.

A pesquisa contou com a participação de 12 (doze) conselheiros municipais, destacando o fato que dois conselheiros assumem assento concomitantemente: um conselheiro, em dois Conselhos (CAE e CME) e o outro conselheiro, nos três Conselhos Municipais (CAE, CME e FUNDEB). Logo, 15 (quinze) representações, sendo (07) sete conselheiros do CME, (04) quatro conselheiros do CAE, e (04) quatro conselheiros do Conselho do FUNDEB, perfazendo um total de quinze representações, conforme especifica $\bigcirc$ Quadro 1, com às representações dos três conselhos de educação.

Quadro 1: Representações dos Conselhos de Educação participantes na pesquisa - 2018

\begin{tabular}{|c|c|c|c|}
\hline CONSELHO & CME & CAE & FUNDEB \\
\hline $\begin{array}{c}\mathrm{N}^{\circ} \\
\text { CONSELHEIROS }\end{array}$ & 07 & 04 & 04 \\
\hline 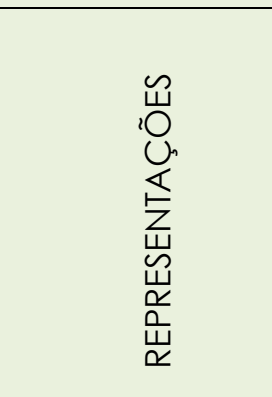 & $\begin{array}{l}\text { 1. Sindicato do Magistério } \\
\text { 2. Professor } \\
\text { 3. Rede Particular } \\
\text { 4. Ordem dos Advogados } \\
\text { 5.Secretaria da Educação } \\
\text { 6. Conselho Municipal dos } \\
\text { Direitos das Crianças e } \\
\text { Adolescentes } \\
\text { 7. Universidade UFSB }\end{array}$ & $\begin{array}{l}\text { 1. Sindicato do } \\
\text { Magistério } \\
\text { 2. Professor } \\
\text { 3. Pais de Alunos } \\
\text { 4. Sociedade Civil } \\
\text { (Sindicato dos } \\
\text { Comerciários) }\end{array}$ & $\begin{array}{l}\text { 1. Poder Executivo } \\
\text { 2. Professor } \\
\text { 3. Diretor Escolar } \\
\text { 4.Téc.Administrativo }\end{array}$ \\
\hline
\end{tabular}

Fonte: Quadro organizado pelas pesquisadoras, a partir do questionário de Pesquisa, 2018.

Argumenta-se, a priori, a ênfase dada por Cury (2007) quando enfatiza que a participação é imprescindível na perspectiva da gestão democrática, ou melhor dizendo, é um dos princípios fundamentais da democracia. Afirma - autor que "é a própria capacidade de participar, sinal maior de democracia" (CURY, 1997, p. 27). Nesse sentido, a participação não significa 
apenas ocupar uma posição numa instituição/conselho ou ser presença na condição de expectador, mas requer acima de tudo comprometimento, cujo diálogo seja o instrumento necessário para a emancipação dos sujeitos envolvidos.

\section{- PERCURSO METOdOLÓgICO E OS RESULTAdOS DA PESQUISA NOS CONSELHOS DE EDUCAÇÃO}

A pesquisa foi desenvolvida numa perspectiva histórica e dialética, considerando a compreensão do universal e do particular, em uma relação do todo com as partes. Inspirada na Pesquisa-Ação defendida por Thiollent (2011), partiu da articulação entre o conhecer e o agir, contribuindo para o debate das questões abordadas. À luz desse entendimento, Thiollent (2011) afirma que a Pesquisa-Ação é uma forma de engajamento sociopolítico a serviço das classes populares, que conta com a participação e ação efetiva das pessoas implicadas nas questões investigadas. Também se utilizou da análise de documentos legais e normativos.

A pesquisa foi desenvolvida em etapas, durante os meses de novembro e dezembro/2018 e de maio a julho/2019. Inicialmente elaborouse um roteiro de questões semiestruturadas, organizadas por blocos temáticos, como mencionamos no item anterior, para conhecer o perfil socioeducacional e profissional dos participantes. No questionário incluiu-se, questões sobre a legislação educacional, com a finalidade de obter informações sobre cada um dos três conselhos e suas vivências, abordando um pouco de sua compreensão acerca da gestão democrática, visando compor o quadro diagnóstico referente aos Conselheiros de Educação existentes no município. A última etapa, formada por seis diálogos coletivos com os Conselheiros de Educação, registrados em áudios, com o consentimento dos participantes, para possibilitar o resgate dos diálogos, garantindo a transparência, o respeito e a responsabilidade dos/nos encontros. A cada encontro, os áudios eram transcritos, organizados em slides e apresentados no encontro seguinte, como instrumento para novas 
discussões a serem analisadas com/no grupo, demonstrando a operacionalização dinâmica dos encontros, onde a reflexão/ação e novos acordos foram construídos pelo/no grupo, em razão de que, na PesquisaAção não existe um planejamento determinado e inflexível, evidenciando o movimento do espiral, característica própria da Pesquisa-Ação.

Identificamos o perfil dos sujeitos da pesquisa, $50 \%$ de conselheiros do sexo masculino e $50 \%$ do sexo feminino. Quanto a titularidade e suplência nos Conselhos de Educação, os dados coletados apontaram que $83 \%$ dos conselheiros participantes da pesquisa são titulares e $17 \%$ são suplentes.

Muito embora entenda-se que um conselheiro deve assumir seu papel de defensor da cidadania, independentemente de sua atuação como titular ou suplente, fazendo do estudo da legislação educacional e de suas investigações o exercício constante das atividades inerentes a sua função, ressalta-se aqui, a perspectiva defendida por Vieira (2016, p. 21-22), como sendo a postura de um conselheiro de educação, quando afirma que é "necessário ter consciência de sua função e responsabilidade para conduzir os trabalhos no órgão. Portanto, ao conselheiro não cabe o improviso, o espontâneo, e sim exige profissionalismo que a função determina".

A pesquisa considerou como relevante identificar o tempo de atuação dos integrantes dos conselhos de educação. Esse aspecto foi analisado tendo por base a ideia de que quanto maior for o tempo de permanência no órgão colegiado, maior é a possibilidade de o conselheiro conhecer o sistema de ensino e acompanhar a efetivação das políticas educacionais. Assim, percebeu-se, conforme o gráfico 1, que três conselheiros atuavam há um ano, quatro conselheiros há um ano e meio, três conselheiros há três anos, e dois conselheiros há oito anos. 
GRÁFICO 1: Tempo de atuação dos Conselheiros de Educação, participantes na pesquisa em 2018

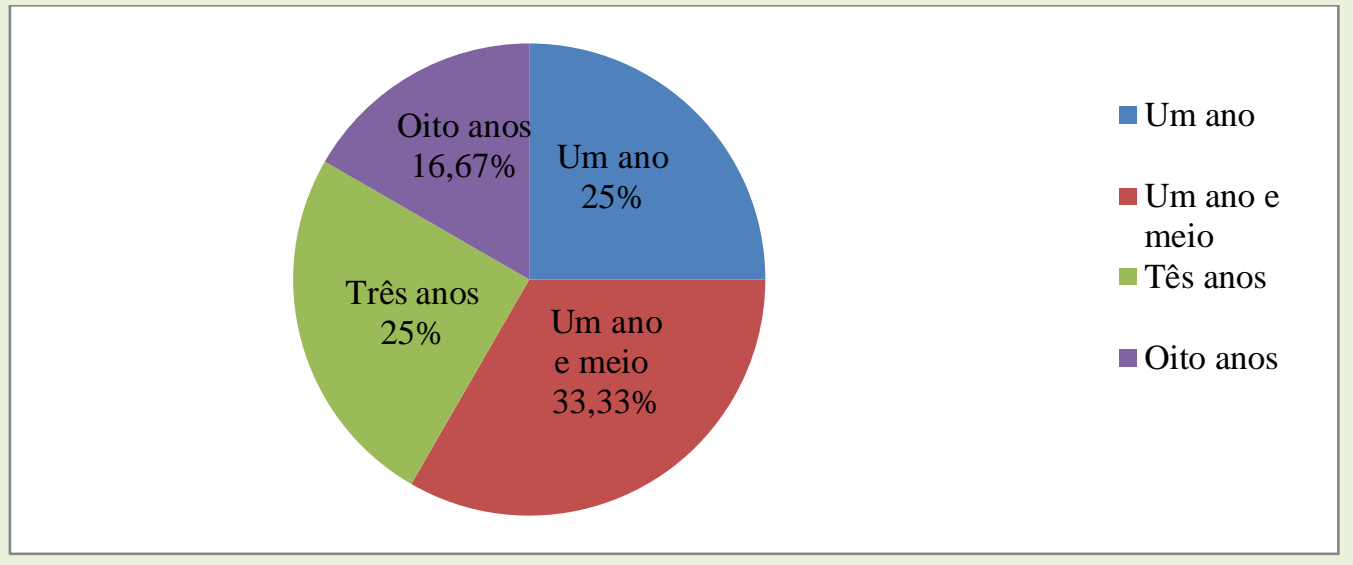

Fonte: Gráfico organizado pelas pesquisadoras, a partir do questionário de Pesquisa, 2018.

De acordo com o Gráfico 1, aproximadamente $75 \%$ dos conselheiros de educação pesquisados já atuam há mais de um ano nas instâncias colegiadas. Compreende-se, portanto, que eles estão no processo inicial de aprendizagem ou de consolidação da dinâmica de funcionamento desses órgãos colegiados e de sua funcionalidade dentro do sistema municipal de ensino. Em maior parte, os mandatos dos conselheiros de educação variam entre dois ou três anos, podendo ser renovados por igual período. Esse dado revela uma informação signiticativa, primeiro por permitir um intercâmbio com os conselheiros que já atuam com mais experiência na função, e em segundo, por proporcionar maior tempo para o conhecimento $e$ monitoramento das políticas educacionais vigentes no município.

Quanto a composição dos conselhos de educação, de membros titulares e suplentes, eleitos e/ou indicados por suas respectivas entidades e órgãos e nomeados pelo Prefeito, conforme detalha o Quadro 2, 58,33\% dos conselheiros foram eleitos entre seus pares, e $41,67 \%$ dos conselheiros foram indicados respectivamente por seus órgãos. Esses dados revelam ainda que a forma de indicação a órgãos colegiados, quando já se possui a possibilidade de realizar eleição, persiste em algumas instâncias públicas. 
Quadro 2: Composição dos Conselhos de Educação por meio de eleição e/ou indicação, participantes na pesquisa - 2018

\begin{tabular}{|l|l|}
\hline \multicolumn{1}{|c|}{ REPRESENTAÇÕES ELEITAS } & \multicolumn{1}{c|}{ REPRESENTAÇÕES INDICADAS } \\
\hline Rede Particular & Executivo Municipal \\
\hline Pais de Alunos & Secretaria da Educação \\
\hline Professores & Ordem dos Advogados da Bahia (OAB) \\
\hline Sociedade Civil & Universidade Federal do Sul da Bahia \\
\hline $\begin{array}{l}\text { Sindicato do Magistério Municipal } \\
\text { Público }\end{array}$ & $\begin{array}{l}\text { Conselho Municipal dos Direitos da Criança e } \\
\text { do Adolescente }\end{array}$ \\
\hline Diretor Escolar & \\
\hline Técnicos Administrativos & \\
\hline
\end{tabular}

Fonte: Quadro organizado pelas pesquisadoras, a partir do questionário de Pesquisa, 2018.

Ainda no que se refere ao processo de composição nos conselhos, por meio de eleição e/ou de indicação dos conselheiros de educação, diversos critérios foram elencados como justificativa para o mandato de conselheiro municipal, dentre eles, destacam-se: envolvimento nas discussões dos problemas da educação, voluntariedade, participação ativa na escola, condições de contribuir na fiscalização dos recursos vindos para a educação, conhecimento de gestão e de políticas educacionais, participação assídua em reuniões de outro conselho e pelo interesse em atuar na condução e planejamento das políticas públicas educacionais municipais.

Para Thiollent (2011) a participação necessita de engajamento político, participação e ação efetiva de pessoas implicadas, logo, os conselhos de educação necessitam de conselheiros com disposição, conhecimento e comprometimento junto as questões educacionais, para coletivamente atuar no desenvolvimento de ações no contexto da sociedade.

Em relação a participação dos conselheiros de educação em outros conselhos existentes no município, identificamos que $25 \%$ dos participantes da pesquisa, conforme o gráfico 2, participam em mais de um conselho e; pouco mais de $30 \%$ deixaram de informar esse dado. Esses sujeitos integram a composição de conselhos municipais, a saber: Conselho de Saúde, Conselho Municipal do Desenvolvimento Rural Sustentável, Conselho da Fundação Marimbeta, Conselho de Desenvolvimento Urbano, Conselho 
Municipal da Criança e do Adolescente e Conselho Universitário. A participação dos conselheiros de educação em outros conselhos municipais foi apontada pelos conselheiros como possibilidade de fortalecimento das ações colegiadas no âmbito municipal, oportunizando refletir com outras esferas públicas as questões educacionais, visando mobilização para garantir a educação, enquanto direito inalienável.

Contudo, nos diálogos com/no grupo promovidos pela pesquisa, também foi possivel perceber a dificuldade encontrada pelos conselheiros em acompanhar as atividades desenvolvidas nos diferentes conselhos que representam, visto que também exercem funções profissionais. Alguns conselheiros externaram não possuir carga horária disponível para atuação efetiva no órgão, e para outros, o não recebimento de ajuda de custo para o transporte, principalmente para atender as convocações de reunião mensal e extraordinária, dificulta a viabilidade do trabalho.

GRÁFICO 2: Participação dos Conselheiros de Educação em outros conselhos municipais. Integrantes da pesquisa em 2018

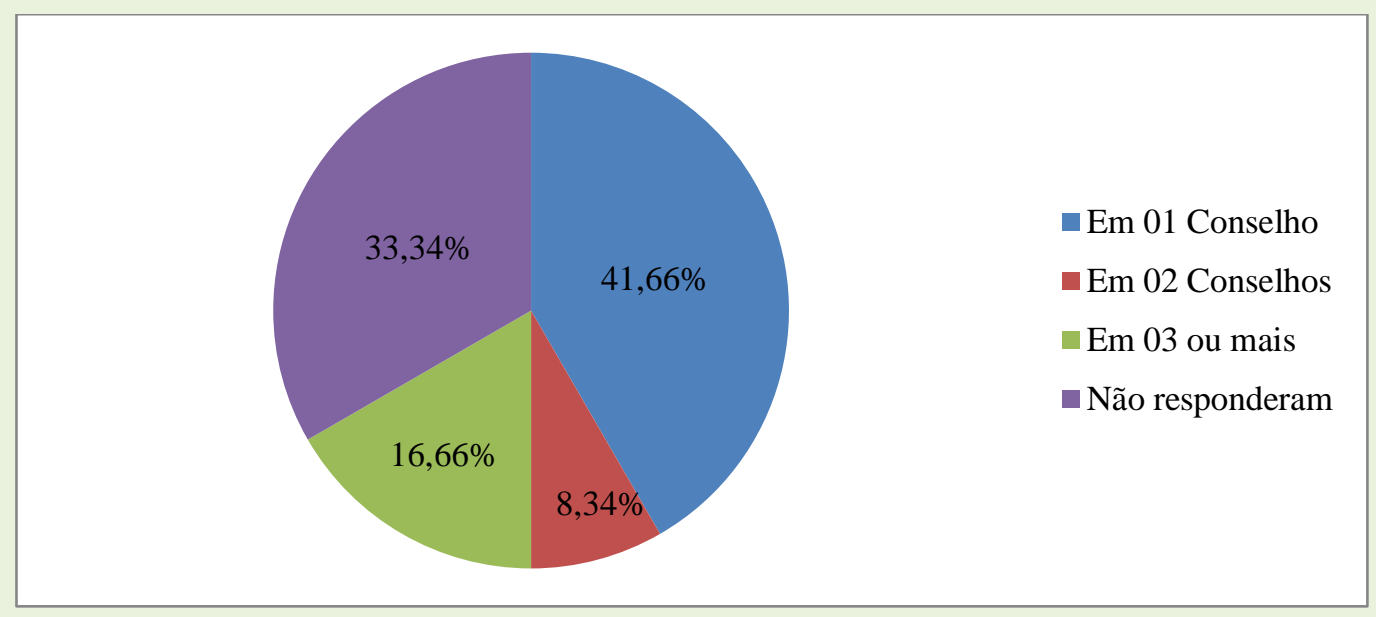

Fonte: Gráfico organizado pelas pesquisadoras, a partir do questionário de Pesquisa, 2018.

O conhecimento acerca do papel do conselho e das atribuições dos conselheiros de educação também é um aspecto fundamental para a atuação consciente na política educacional, e para compreender a função dos conselhos enquanto democratizadores educacionais. Segundo o Programa Nacional de Fortalecimento dos Conselhos Escolares em 
publicação no Caderno "Conselhos Escolares: Uma Estratégia de Gestão Democrática da Educação Pública" elaborado por Genuíno Bordignon, (BRASIL, 2004, p.23-24), apresenta as quatro principais funções do Conselho: Deliberativa - competência específica para decidir sobre determinadas questões; Consultiva - caráter de assessoramento, exercida por meio de interpretação da legislação; Fiscal - competência legal para fiscalizar e legitimar o cumprimento de normas e; Mobilizadora - que situa o conselho numa ação de mediação entre o governo e a sociedade. A função Normativa, é realçada por Cury (2006, p.42) que a configura como a mais nobre de todas as funções

[...] é ela que dá a verdadeira distinção de um Conselho de Educação. [...] ela se dá por meio de Pareceres e Resoluções e, para tanto, ela deve ter provisão legal e sua intencionalidade é a de executar o ordenamento jurídico que lhe dá fundamento.

No que se refere ao nível de formação dos conselheiros de educação, entende-se ser esse um fator relevante, e que pode qualificar a atuação dos conselheiros de educação. Contudo, vale salientar que não existe nível de escolarização exigido para participar de um conselho. O Gráfico 3 apresenta a escolaridade dos conselheiros de educação do município, e constatou-se que a maioria dos conselheiros possui pós-graduação lato sensu (especialização), e em áreas como: gestão escolar, gestão participativa, psicopedagogia institucional, gestão do trabalho pedagógico e educação para as relações étnico-raciais. Essas formações indicam que os conselheiros buscam possibilidades de implementar ações, considerando seus conhecimentos complementares na área educacional, o que contribui para o desenvolvimento das linhas de atuação dos conselhos no sistema onde estão inseridos. 
GRÁFICO 3: Escolaridade dos Conselheiros de Educação, participantes na pesquisa em 2018

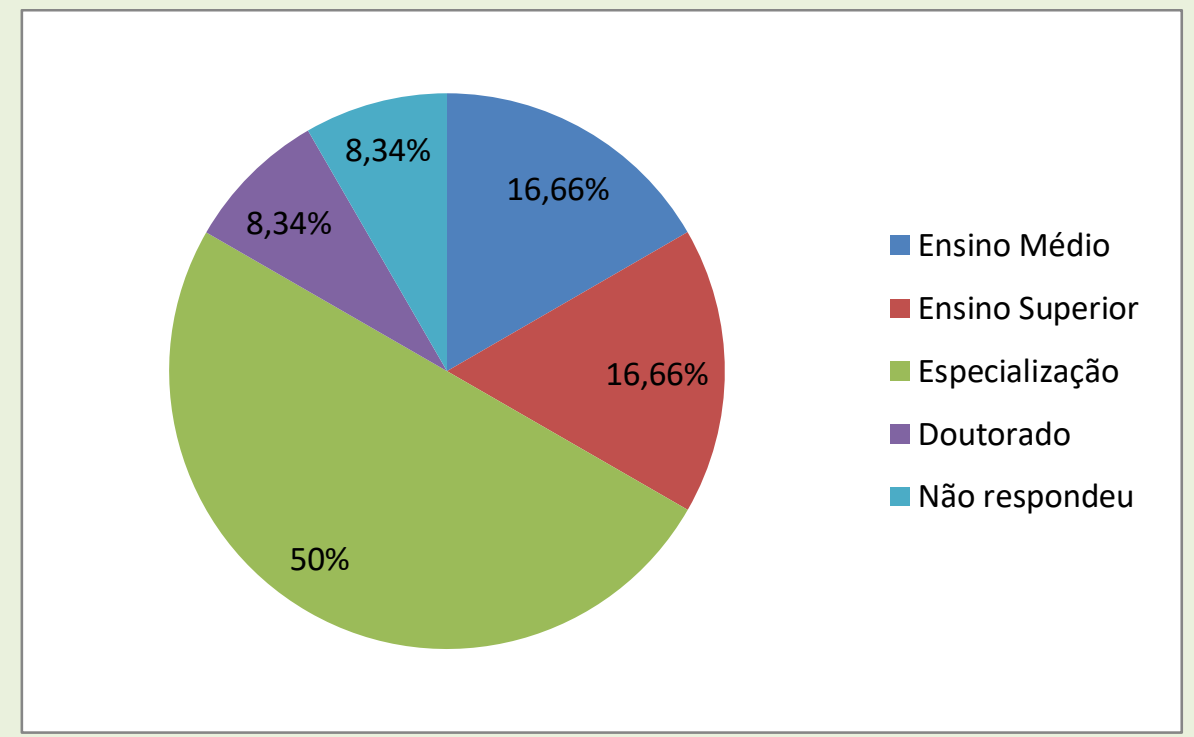

Fonte: Gráfico organizado pelas pesquisadoras, a partir do questionário de Pesquisa, 2018.

Os dados do Gráfico 3 confirmam que os conselheiros de educação em sua grande maioria têm nível de formação superior. Outro aspecto a destacar dessa formação, é que 58,34\% desse total fez especialização e um doutorado na área de educação, o que favorece aos debates necessários para tomada de decisão pelos órgãos, já que buscam por formação complementar. Essa formação é potencializadora a qualificar os debates e as decisões coletivas que precisa o órgão tomar, fazendo dos conselhos de educação espaços coletivos de decisões, com condições de acompanhar e monitorar a política educacional em nível municipal. Um outro aspecto a considerar dessa formação está relacionado à experiência dos conselheiros nos conselhos, já que $58,33 \%$ deles, conforme gráfico 1 , têm até um ano e meio como integrante de um dos três conselhos. Bordenave (1992) afirma que [...] participação proporciona o crescimento do grau de consciência crítica dos cidadãos, amplia as possibilidades de reivindicação, além de fortalecer o grau da legitimidade do poder público quando responde às necessidades reais da população (BORDENAVE, 1992, p. 20-21).

Além disso, o nível de conhecimento do conselheiro perpassa também pela responsabilidade do órgão em oportunizar formação ao conselheiro, no 
próprio órgão ou em outras instâncias em âmbito estadual ou nacional. Essa prática viabiliza a qualificação dos sujeitos que compõem o conselho, permitindo-lhes acompanhar as políticas educacionais dentro do Sistema Municipal de Ensino.

Para o cumprimento da função que exerce o conselheiro, faz-se necessário um aprendizado cotidiano, no exercício da experiência de participação, para que se possa exercer, de acordo a premissa defendida por Lima (2009), o controle social por parte dos movimentos populares e sociais voltados para a educação, quando assevera [...] Conselho democrático, participativo e atuante só existe se nele houver uma composição de sujeitos democráticos, participativos e atuantes (LIMA, 2009 , p. 15).

Quanto à atividade profissional dos conselheiros de educação, conforme gráfico 4 , percebeu-se que $75 \%$ dos conselheiros são profissionais da educação, e encontram-se desenvolvendo atividades como docentes ou técnicos na Secretaria da Educação; $25 \%$ estão fora do cenário educacional, desenvolvendo atividades voltadas para a agricultura, comércio e atuando como profissional liberal, porém, na compreensão do grupo, traz experiências significativas para a reflexão de como a educação tem sido analisada por quem encontra-se mais distante do sistema municipal de ensino. 
GRÁFICO 4: Atividade Profissional dos Conselheiros de Educação, participantes na pesquisa - 2018

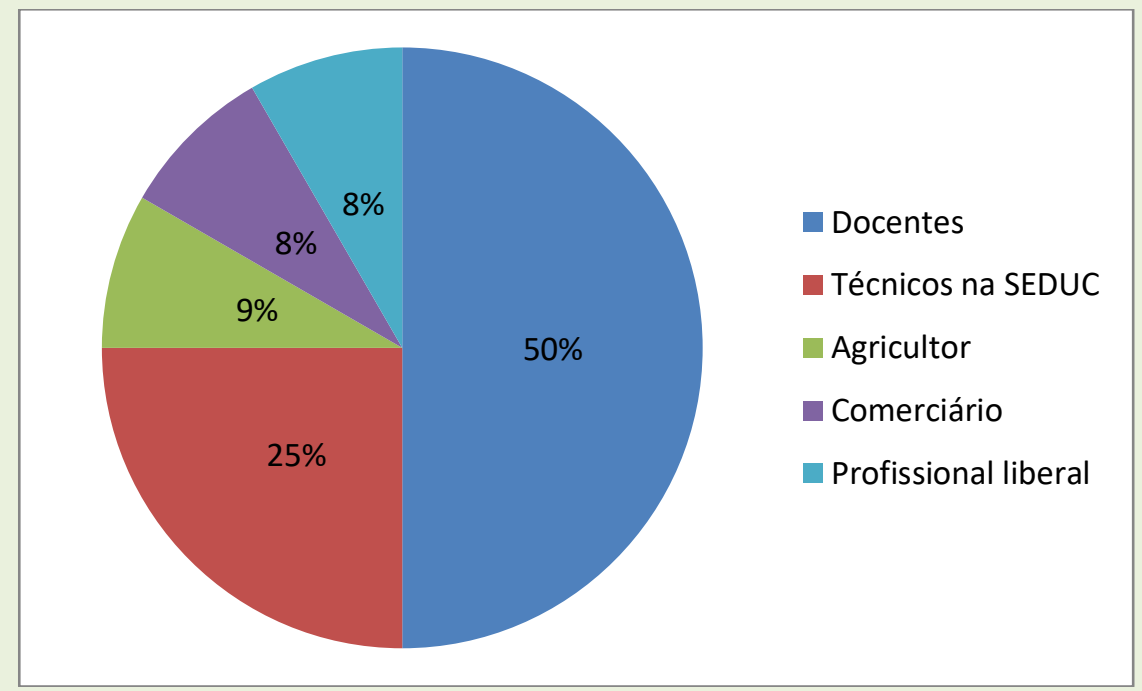

Fonte: Gráfico organizado pelas pesquisadoras, a partir do questionário de Pesquisa, 2018.

Dos $75 \%$ conselheiros de educação associados às atividades no serviço público municipal, $50 \%$ são docentes, o que de certa forma são sujeitos implicados diretamente com as políticas educacionais desenvolvidas no município e nas escolas. A experiência docente, de certa forma, evidencia um nível de conhecimento e interação com a realidade educacional, dando aos conselheiros de educação condições de interpretar a realidade, seu papel no sistema e assumir uma práxis, como afirma Vázquez (1968), em ações transformadoras. Além disso, como destacamos anteriormente, a experiência docente pode auxiliar na atuação dos conselheiros, mesmo que tenham pouco tempo de participação no conselho.

Outro aspecto da pesquisa está relacionado a perspectiva de identificar o nível de conhecimento dos conselheiros de educação acerca da legislação educacional. Desse modo, elencamos algumas legislações pertinentes aos três conselhos, como por exemplo, LDB/1996, Plano Nacional de Educação de 2001 e de 2014, FUNDEB, e solicitamos que identificassem e descrevessem às finalidades de cada legislação. O Gráfico 5 apresenta o quantitativo de conselheiros de educação que sinalizaram conhecer as referidas legislações. As siglas que aparecem no Gráfico 5 referem-se às Leis, 
Resoluções, Planos, Programas, Diretrizes, Portarias e Emenda Constitucional, relacionadas à educação nacional.

GRÁFICO 5: Legislações Educacionais conhecidas pelos Conselheiros de Educação, participantes na pesquisa em 2018

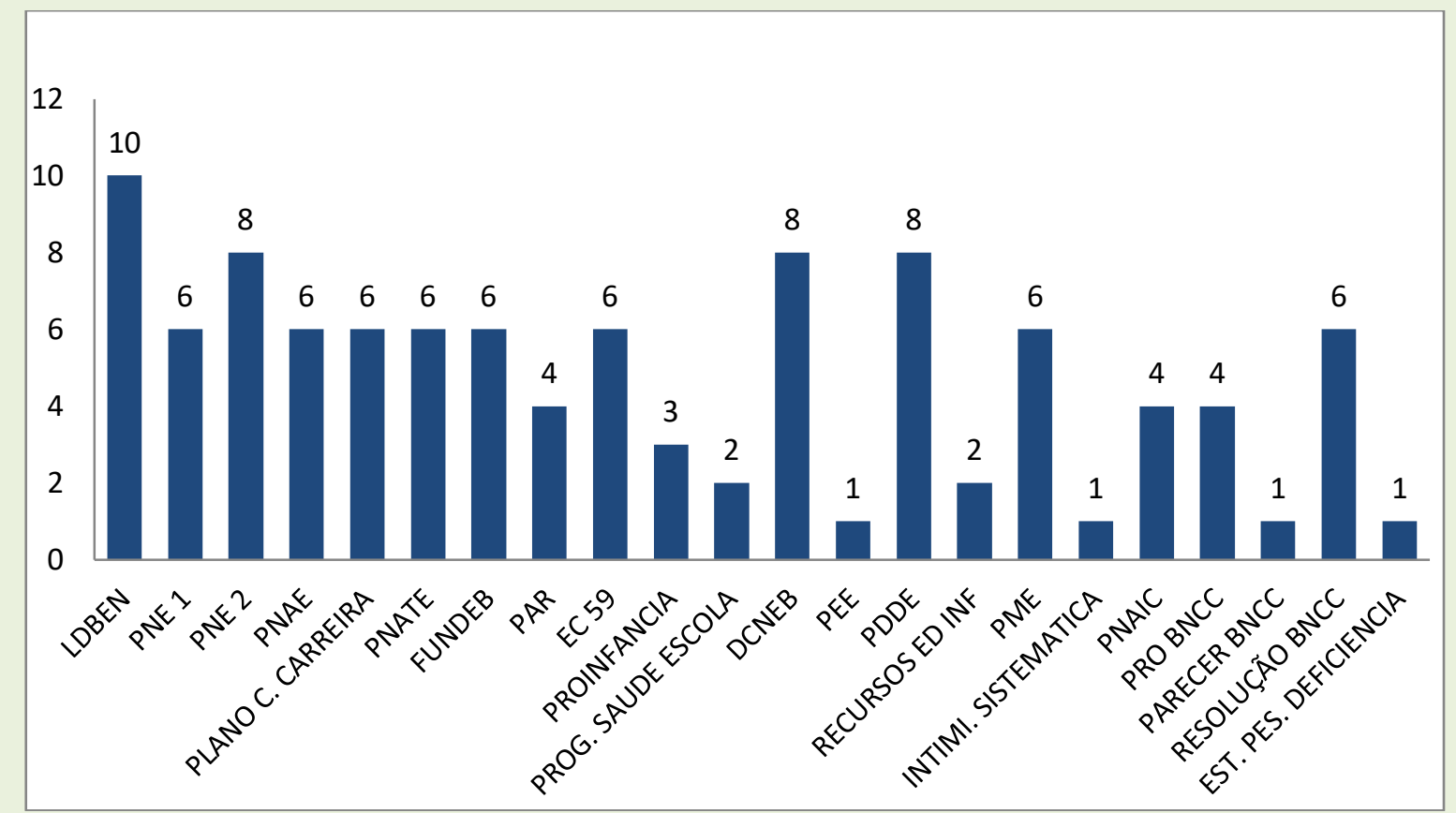

Fonte: Gráfico organizado pelas pesquisadoras, a partir do questionário de Pesquisa, 2018.

O estudo da legislação se constitui como uma atividade permanente em um conselho de educação. Não existe defesa da bandeira da educação sem conhecimento da legislação educacional. No estudo, apresentamos primeiro a Lei de Diretrizes e Bases da Educação Nacional, criada para garantir o direito de todos a uma educação pública, gratuida e de qualidade, e que organize a educação nacional. Dessa legislação, foram criadas outras normas, regulamentações e leis complementares relativos à educação, que expomos na sequência para identificação pelos conselheiros.

Conforme Cury (2006), diversos motivos justificam a necessidade do estudo, dentre eles: elaboração de pareceres e normativas; sistematização de ações no exercício das atividades na Secretaria de Educação ou na Escola, e pela necessidade de interpretar a aplicabilidade da legislação em âmbito municipal. $\bigcirc$ estudo de acordo ainda com o autor, possibilita além 
da compreensão da legislação educacional, à obtenção de condições de identificar o legal e o legítimo exercício interpretativo da lei pelos conselheiros da educação municipal (CURY, 2006).

Ainda segundo o autor, o conselheiro de educação no exercício da função normativa deve conhecer e ter cuidado ao interpretar a legislação, e que ela "[...] não pode se dar contra legem, ultra legem ou praeter legem. Ela só pode se dar secundum legem e intralegem [...]" (p. 42). Isso segundo o autor, significa que, "nesse sentido, importa não confundir o legal e legítimo exercício interpretativo da lei sob forma de norma com seu abuso" (p. 42). A função de conselheiro implica, assim, segundo o autor, "um ser o intelectual da legislação da educação escolar para, em sua aplicação ponderada, garantir um direito da cidadania" (p. 42). Logo, conhecer a legislação requer "estudos e investigações que o conduza a conhecimentos específicos para o exercício das tarefas próprias da função" (p. 42), é um ato profissional com a atividade precípua de um conselho de educação.

Da análise do gráfico 5, das respostas dos conselheiros, para este artigo, lembramos que este gráfico foi mostrado aos conselheiros e realizado debate com/no grupo sobre o conhecimento de cada legislação. Conforme os dados, dos 12 conselheiros participantes da pesquisa, 10 informaram conhecer a LDB; 08 conselheiros responderam conhecer o Plano Nacional de Educação (2014-2024) - PNE 2; 6 conselheiros conhecem o FUNDEB; 6 conselheiros responderam conhecer a BNCC; 6 conselheiros conhecem o Plano Municipal de Educação. O gráfico expõe que alguns representantes dos conselhos, considerados guardiões da lei, não conhecem as principais legislações, e esse conhecimento é necessário como suporte para elaborar normas e resoluções municipais, e fazer cumprir a lei.

Como destacamos anteriormente, a experiência docente pode auxiliar na atuação dos conselheiros, principalmente quando identificamos que $58,33 \%$ dos conselheiros, conforme gráfico 1, têm até um ano e meio como integrante de um dos três conselhos. Contudo, a experiência docente somente não qualifica o trabalho de atuação dos conselheiros. Na discussão com/no grupo, concluiu-se com a proposta de organização de cursos, 
formações, promovidos pelos próprios conselhos, e como é uma realidade compartilhada nos três conselhos, um processo inicial de interação entre esses órgãos e iniciar o processo de relação entre os conselhos.

Nas discussões com/no grupo, foi possível identificar como acontece esse processo de estudo da legislação por parte dos conselheiros de educação. As informações assinalaram que os conselheiros estudam em casa, na universidade, em seminários ou cursos de aperfeiçoamento. Ocorre também por meio de momentos de formação específica para conselheiros, em reuniões nos conselhos ou em encontros da União Nacional dos Conselheiros Municipais de Educação (UNCME). Esses diálogos reforçaram a importância de organização, pelos conselhos, de ação conjunta de fortalecimento dos conselhos e, principalmente, visando o fortalecimento da gestão democrática da educação no Sistema Municipal de Ensino (SME).

A interação entre os conselhos para troca de informações, principalmente no que se refere às atividades desenvolvidas, ainda é considerada um grande desafio ao grupo. Essa constatação foi possível identificar nos diálogos com/no grupo, em que expuseram as dificuldades em manter as reuniões mensais de cada conselho, o excesso de demanda a ser atendida. Tudo isso dificulta a aproximação com os demais conselhos para compartilhar as atividades e realizar ações conjuntas de forma a acompanhar o desenvolvimento da educação municipal. Para alguns conselheiros o trabalho que realizam não tem condições de compartilhar com outros colegiados municipais e nem com a sociedade civil.

O estudo de Silva (2016, p.224), demonstra que quando os Conselhos da Educação são melhor capacitados para o desenvolvimento de seus trabalhos e com uma melhor estrutura de funcionamento, é possível ter

Iniciativa de viabilizar as condições necessárias para que outros membros da sociedade participem de suas decisões - além daqueles que járepresentam determinados segmentos sociais e compõem o colegiado -, se quiserem contar com a contribuição daqueles que, justamente, serão os maiores beneficiados com a melhoria da qualidade do ensino público. 
Nas discussões, os conselheiros expuseram que sentem necessidade de tornar público a função/atuação dos conselheiros de educação, até então, pouco conhecida pela sociedade civil, justificando a grande importância desse ato para o fortalecimento da gestão democrática da educação no sistema municipal de ensino. A formalização da proposta pelo grupo está contida em um documento, que organiza um plano de ação para conselheiros de educação, e nele consta a realização de uma audiência pública com os demais conselhos municipais, integrantes do Ministério Público, representantes do Legislativo e todos aqueles que têm compromisso com as questões educacionais, objetivando publicizar a finalidade dos conselhos de educação a toda sociedade, apresenta também uma proposta de um curso de formação para conselheiros, proposto pelos integrantes dos três conselhos.

\section{CONSIDERAÇÕES FINAIS}

No texto apresentamos a função e atuação dos Conselheiros de Educação do Conselho Municipal de Educação (CME), Conselho de Alimentação Escolar (CAE) e Conselho de Acompanhamento e Controle Social do Fundo de Manutenção e Desenvolvimento da Educação Básica e de Valorização dos Profissionais de Educação (FUNDEB) de um município do sul da Bahia, para atingir o objetivo da pesquisa, qual seja, ações de fortalecimento da gestão democrática da educação em um Sistema Municipal de Ensino (SME).

Foi realizado um questionário diagnóstico e seis encontros com o grupo de 12 conselheiros, inspirados na Pesquisa-Ação defendida por Thiollent (2011), para discussão da função e atuação dos conselhos.

Identificamos que $75 \%$ dos conselheiros são profissionais da educação, e encontram-se desenvolvendo atividades como docentes ou técnicos na Secretaria da Educação, o que de certa forma os tornam sujeitos implicados diretamente com as políticas educacionais desenvolvidas no município e nas escolas, e essa aproximação com a educação auxilia nas decisões dos conselhos; os $25 \%$ que estão fora do cenário educacional, desenvolvem 
outras atividades, mas não foram consideradas como problemas, pois, são experiências significativas para a reflexão de como a educação tem sido analisada por quem encontra-se mais distante do sistema municipal de ensino.

Além da experiência docente ser considerada como positiva na atuação do conselheiro, a formação também é assinalada como importante, apesar de não ser exigido nível de escolarização para participar de um conselho. Observa-se que $75 \%$ dos conselheiros de educação têm formação em nível superior, e desses, 58,34\% têm especialização e um, tem doutorado na área de educação. Para os conselheiros esse perfil pode ser considerado importante para a interpretação da lei e tomada de decisões, mesmo que $58,33 \%$ deles, tenham até um ano e meio como integrante de um dos três conselhos.

Embora os conselheiros assinalem o esforço em compreender a função e atuação dos conselhos justificada pela formação e experiência docente, identificamos nos diálogos coletivos com/no grupo, que boa parte dos conselheiros não conhecem as principais legislações, e esse conhecimento é de extrema importância, conforme destacado por alguns autores no decorrer do texto, e necessário para elaborar normas e resoluções municipais, e fazer cumprir a lei.

Após a discussão com/no grupo, o desafio de qualificar o conselheiro pode ser atenuado pela organização de cursos, formações, promovidos pelo próprio conselho, e como é uma realidade compartilhada nos três conselhos, um processo inicial de interação entre esses órgãos.

O estudo da legislação se constitui uma atividade permanente em um conselho de educação, e sem esse conhecimento da legislação educacional, todo o trabalho do conselho pode ficar comprometido, ou improvisado, o que de acordo com Cury (2006), eivado de vícios.

Os diálogos no/com o grupo, reforçaram a importância de organização, pelos conselhos, de ação conjunta e, principalmente, visando - fortalecimento da gestão democrática da educação no Sistema Municipal de Ensino (SME). A interação entre os conselhos para troca de 
conhecimentos e informações, principalmente no que se refere às atividades desenvolvidas, ainda é considerada um grande desafio ao grupo. Contudo, a organização coletiva do curso pode ser considerada como o primeiro passo para aproximação e interação entre os conselhos para tomada de decisões coletivas de forma a acompanhar o desenvolvimento da educação municipal.

Tornar público a função/atuação dos conselheiros de educação, até então, pouco conhecida pela sociedade civil, tem grande importância para o fortalecimento da gestão democrática da educação, e essa ação pode ser possibilitada quando há integração de conselhos da educação, que juntos têm compromisso com as questões educacionais, objetivando publicizar a finalidade dos conselhos de educação a toda sociedade.

\section{REFERÊNCIAS}

BAHIA. Secretaria do Planejamento. Perfil dos Territórios de Identidade/: SEI, 2018.3 v. p.252 (Série territórios de identidade da Bahia, v. 3). Disponível em: <http://www.seplan.ba.gov.br> Acesso em: 12 dez 2018.

BORDENAVE, J. E. D. O que é Participação. São Paulo: Brasiliense, 1992.

BRASIL. Ministério da Educação. Secretaria de Educação Básica. Programa Nacional de Fortalecimento dos Conselhos Escolares: Conselhos Escolares: Uma Estratégia de Gestão Democrática da Educação Pública/elaboração Genuíno Bordignon. Brasília: MEC, SEB, 2004.

CURY, C. R. J.; HORTA, J. S. B.; BRITO, V. L. A. Medo à Liberdade e Compromisso Democrático: LDB e Plano Nacional de Educação. São Paulo: Editora do Brasil, 1997.

CURY, C. R. J. Conselhos de educação: fundamentos e funções. Revista Brasileira de Política e Administração da Educação - RBPA. Brasília, v. 22, n. 1 p. 41-67. jan./jun. 2006.

CURY, C. R. J. A gestão democrática na escola e o direito à educação. Revista Brasileira de Política e Administração na Educação RBPAE. Brasília, v. 23, n. 3 p. 483-495. set./dez. 2007.

DOURADO, L. F. Gestão da educação escolar. Brasília: Universidade de Brasília, Centro de Educação a Distância, 2006. 
LIMA, A. B. Conselho de Educação e Controle Social: a necessidade de movimentos sociais, 2009. Disponível em:

<http://www.anped.org.br/sites/default/files/gt03-5615-int.pdf>. Acesso em: 18 dez 2018.

SANTOS, P. E. Institucionalização dos conselhos municipais de educação nas capitais brasileiras: a luta por uma nova hegemonia política. 2014. Tese (Doutorado em Educação) - Curso de Pós-Graduação em Educação, Universidade Federal de Goiás, Goiânia, 2014.

SILVA, N. R. G. No interior de um Conselho Municipal de Educação: análise de um colegiado que se fez itinerante. Revista Exitus, 4(1), 203-225, 2016.

THIOLLENT, M. Metodologia da Pesquisa-Ação.18 ed - São Paulo: Cortez, 2011.

VÁZQUEZ, A. S. Filosofia da Práxis. Rio de Janeiro: Civilização Brasileira, 1968.

VIEIRA, E. P. A importância dos Conselhos Municipais na garantia dos direitos das crianças à Educação Infantil. In: VIEIRA, E. P.; ALVES, C. M. S. D.; SEDANO, L. Educação Infantil em debate. Curitiba: CRV, p.17-25, 2016.

Recebido em: 09 de setembro de 2020 Aprovado em: 02 de novembro de 2020 Publicado em: 24 de novembro de 2020 